\title{
PERANCANGAN APLIKASI CADANGAN COUNTER CHECK-IN LION AIR PADANG DENGAN MENGGUNAKAN BAHASA PEMROGRAMAN VISUAL BASIC 6.0
}

\author{
Veni Wedyawati \\ Sistem Informasi, Sekolah Tinggi Teknologi Industri Padang \\ Email : veniwedyawati@sttind.ac.id
}

\begin{abstract}
Abstrak : Lion Air merupakan sebuah maskapai penerbangan yang memiliki tingkat minat lebih tinggi di Indonesia. Maskapai ini melayani penerbangan dalam negeri maupun international. Lion Air merupakan Maskapai pertama di Indonesia yang mengggunakan armada jenis Boeing 737-900ER dengan jumlah yang cukup banyak. Armada maskapai tersebut banyak digunakan untuk penerbangan domestik dan International. Pada saat ini masih banyak kendala yang terdapat pada PT.Lion Air terutama pada saat Check-in Tiket. Apabila jaringan tidak terkoneksi proses Check-in tiket tidak dapat dilakukan dengan sistem komputerisasi hanya bisa dilakukan secara manual. Agar proses check-in tiket bisa tetap dilakukan sebaiknya ada sistem pengganti untuk melakukan check-in agar pekerjaan yang dilakukan tetap berjalan dengan baik dan efisien. Aplikasi yang digunakan yaitu pemrograman Visual Basic 6.0 dan memakai database untuk menyimpan data-data, untuk penginputan dan penyimpanan. Dengan adanya Program Aplikasi ini diharapkan akan dapat mengoptimalkan sistem yang sedang berjalan, agar menghasilakan data yang tepat, dan membantu PT. Lion Air dalam Proses Check-in pada saat jaringan tidak terkoneksi.
\end{abstract}

Kata Kunci : Sistem, Check-in, Visual Basic 6.0

\begin{abstract}
Lion Air is an airline that has a higher level of interest in Indonesia. This airline serves domestic and international flights. Lion Air is the first airline in Indonesia to use a large number of Boeing 737-900ER fleets. The airline fleet is widely used for domestic and international flights. At this time there are still many obstacles that exist in PT. Lot Air especially during Ticket Check-in. If the network is not connected, the ticket check-in process cannot be done with a computerized system, it can only be done manually. In order for the ticket check-in process to continue to be carried out, there should be a replacement system to check-in so that the work done is still running well and efficiently. The application used is Visual Basic 6.0 programming and uses a database to store data, for inputting and storing. With the existence of this Application Program, it is expected that it will be able to optimize the current system, so that the right data is generated, and help PT. Lion Air in the Check-in Process when the network is not connected.
\end{abstract}

Keyword : System, Check-in, Visual Basic 6.0

\section{PENDAHULUAN}

Seiring kemajuan ilmu pengetahuan dan teknologi saat ini, banyak komputer digunakan di perusahaan, instansi dan sekolahan, serta dalam berbagai aktivitas dan pekerjaan. Dengan adanya komputer pemberian layananan dalam berbagai bidang menjadi lebih baik, cepat dan efisien. Dalam suatu perusahaan atau organisasi yang bergerak dibidang apapun peran komputer sangat penting sebagai penunjang kelancaran pelaksanaan suatu kegiatan dengan cepat dan akurat. Peranan komputer ini di harapkan dapat menunjang keberhasilan dan perkembangan suatu perusahaan atau organisasi.

PT. Lion Air Cabang Padang merupakan suatu badan usaha yang bergerak di bidang penerbangan. Maskapai penerbangan ini dikomandoi oleh Rusdi Kirana dan keluarganya. Dalam perkembangannya, Maskapai penerbangan ini berencana untuk bergabung dengan International Air Transport Asosiation 


\section{HASIL DAN PEMBAHASAN}

\section{Implementasi Sistem}

Implementasi sistem adalah suatu prosedur yang dilakukan pada tahap sistem dalam dokumen yang disetujui dan menguji kemudian menginstal dan menggunakan program yang dibuat.

Tujuan Implementasi sistem adalah sebagai berikut :

1. Menyelesaikan desain sistem yang ada dalam dokumen sistem yang disetujui

2. Menulis, menguji dan memdokumentasikan program dan prosedur-prosedur yang diperlukan oleh dokumen desain sistem yang diuji.

3. Memastikan bahwa personal dapat mengoperasikan sistem yang telah dibuat.

4. Memastikan bahwa koneksi kesistem yang baru saja berjalan dengan benar.

5. Memperhitungkan bahwa sistem sesuai dengan kebutuhan pemakai.

Untuk merancang dan mengimplementasikan sistem yang dirancang diperlukan sebuah alat berupa komputer sebagai media yang dapat membantu dalam pengaplikasikannya. Pada komputer terdapat tiga komponen penting yang seperti hardware, software dan brainware.

\section{Tahap Implementasi}

Tahap dalam implementasi sistem ada tiga, yaitu :

1. Perencanaan dan proses implementasi

Perenacanaan dan proses implementasi merupakan langkah penting dalam penerapan dalam sistem baru. Tujuan adalah agar penerapan sistem baru ini betulbetul sesuai dengan tujuan dan sasaran pengadaannya.

2. Pelaksanaan proses implementasi Pelaksanaan proses implementasi bertujuan untuk melakukan proses penerapan sistem baru.

3. Pelatihan Personil
Personil pengguna sistem merupakan orang yang pemengang peran penting dalam pemanfaatan sistem baru. Pelatihan personil dilakukan dengan tujuan agar personil yang ditunjuk untuk menjalankan sistem baru tidak mengalami kesulitan dan pengoperasiannya.

\section{Pengujian Sistem}

Pada bab ini akan dijelaskan lebih rinci tentang sistem yang telah dibuat. Pengujian sistem dilakukan untuk menguji hubungan antara program aplikasi yang dibuat dengan elemen yang lain dalam sistem informasi. Adapun tujuan dari pengujian sistem ini adalah untuk memastikan semua elemen sistem sudah terhubung dengan baik. Pada pengujian ini sistem akan dilihat perbedaan antara sistem yang lama dengan yang baru. Berikut merupakan penjelasan beserta gambar tentang Perancangan Aplikasi Cadangan Counter Check-in Lion Air Padang dengan Menggunakan Bahasa Pemograman Visual Basic 6.0.

\section{Tampilan Menu Utama}

Dari form menu utama dapat diketahui untuk membuka menu terlebih dahulu membuka password, dan form tersebut terdiri dari 3 menu yaitu menu file, menu laporan data dan menu keluar.

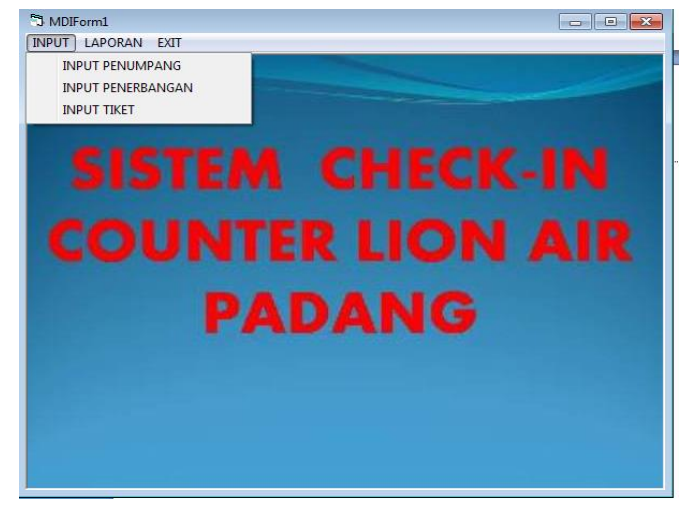

Gambar 1. Tampilan Menu Utama 


\section{Menu Input Data Penumpang}

Untuk mengisi data penumpang Masukan ID_Penumpang, Nama Penumpang, Tempat Lahir, Tanggal Lahir, Jenis Kelamin, Alamat, Status Check-in, kemudian klik tombol Save untuk menyimpan Data. Untuk mengedit Data Penumpang Dan jika ingin merubah data penumpang ,klik tombol Edit dan Tukar data yang di inginkan klik tombol Save. Untuk menghapus data Penumpang Isi ID_penumpang enter lalu Klik tombol Delete.

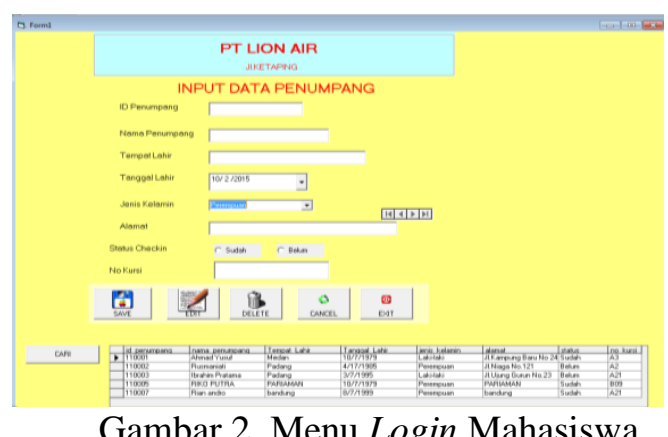

\section{Menu Imput Dat Penerbangan}

Untuk menampilkan Form Input Data Penerbangan

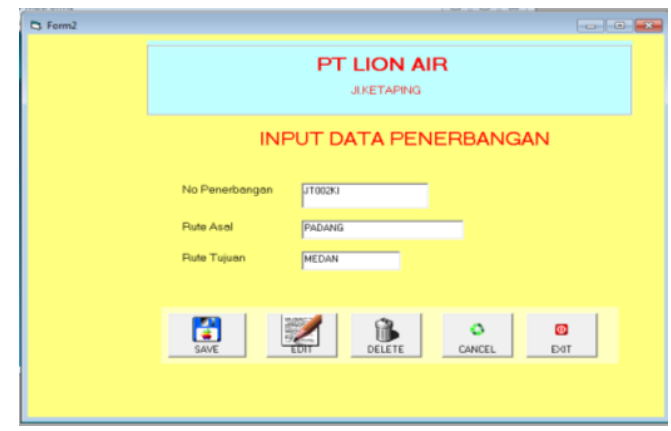

Gambar 3. Menu Input Data Penumpang

\section{Menu Input Data Tiket}

Untuk menampilkan Form Input Data Tiket

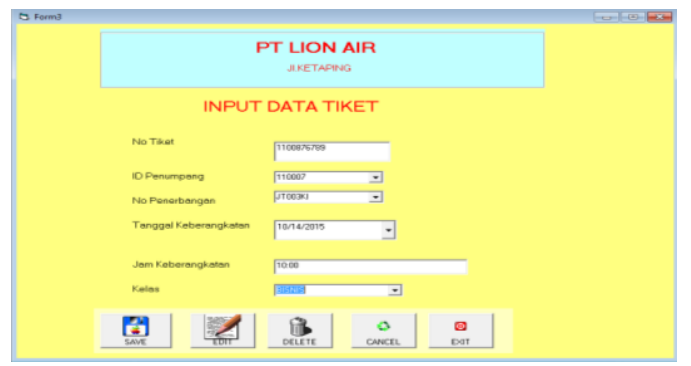

Gambar 4. Menu Input Data Tiket

\section{Tampilan Menu Laporan}

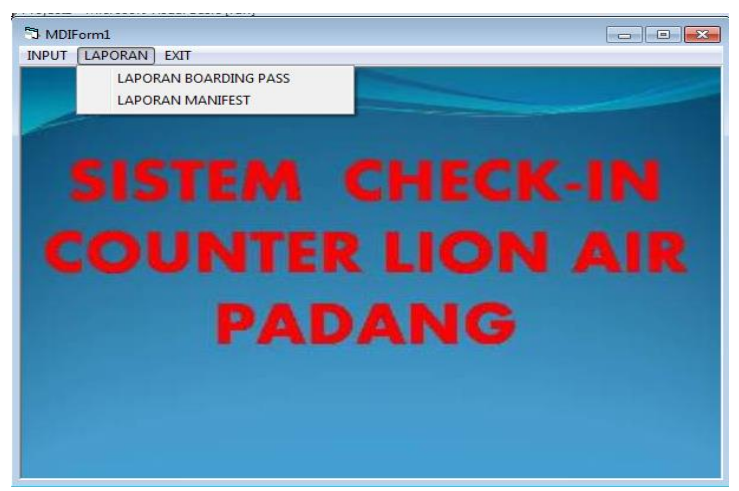

Gambar 5. Menu Laporan

\section{Tampilan Boarding Pass}

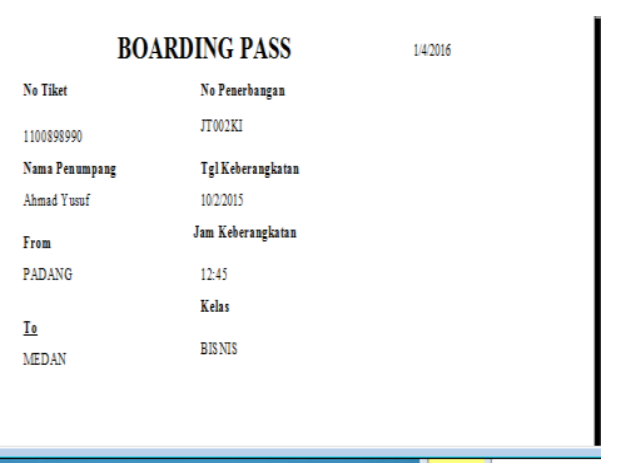

Gambar 6. Tampilan Boarding Pass

\section{Tampilan Form Manifest}

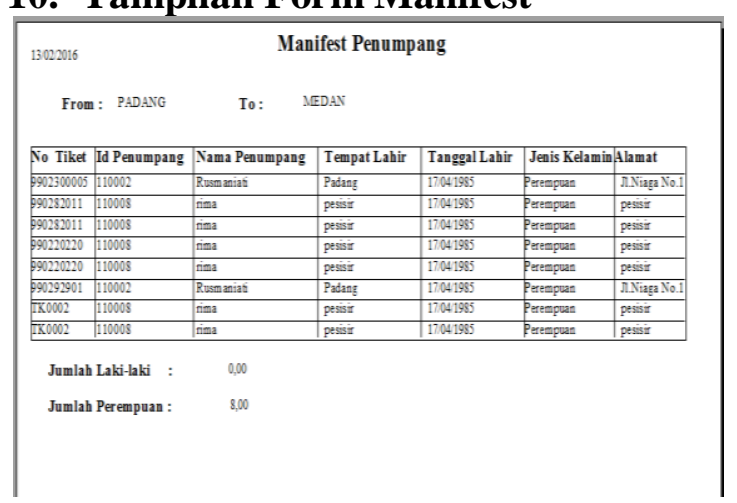

Gambar 7. Tampilan Form Manisfest

\section{KESIMPULAN}

Kesimpulan melakukan penelitian, Aplikasi Pengganti ini dapat diperoleh beberapa kesimpulan sebagai berikut :

1. Dengan adanya perancangan program Aplikasi Visual Basic 6.0 ini agar proses check-in tetap bisa dilakukan meski jaringan tidak terkoneksi, 
sehingga mempermudah karyawan melakukan pekerjaannya dan tidak memakan waktu yang lama.

2. Memberikan pelayanan yang tepat cepat dengan tingkat ketelitian yang lebih tinggi dalam proses pelayanan terhadap penumpang.

3. Tidak terjadinya double seat dan double bording pass saat di atas pesawat dan akan mengakibatkan terjadinya delay.

\section{DAFTAR PUSTAKA}

Fatta, Hanif Al. Analisa \& Perancangan Sistem Informasi untuk keunggulan Bersaing Perusahaan \& Organisasi modern. Yogjakarta: Penerbit Andi. 2007.

Hartama, Dedy Efrizal. Pemrograman web dengan HTML, CSS dan Javascrip. Yogyakarta: Penerbit Andi. 2012. http://www.proweb.co.id/articles/w eb_design/website_adalah.html.

Wahyudi, Bambang,S.Kom, MMSi, Konsep Sistem Informasi dari Bit sampai ke Database, Yogyakarta ,Andi Offset, , 2008.

Arbie, E., Pengantar Sistem Informasi Manajemen, Edisi Ke-7, Jilid 1, Jakarta, Bina Alumni Indonesia, 2000

Kurniadi, Adi, Pemproman Microsoft Visual Basic 6.0, , Jakarta: , PT. Elex Media Komputindo, Januari 2000.

Lani Sidharta, Pengantar Sistem Informasi Bisnis, , Jakarta, P.T. ELEX Media Komputindo, 1995.

Muhyuzir T.D, Analisa Perancangan Sistem Pengolahan Data, Jakarta, Cetakan Kedua, PT. Elex Media Komputindo, 2001 